\title{
Effect of ultrafine grinding and high pressure technology on functional properties of soybean by-products
}

\author{
Fang Wang ${ }^{1,2}$, Valerii Sukmanov ${ }^{1}$, Jie Zeng ${ }^{2}$ \\ 1 - Sumy National Agrarian University, Sumy, Ukraine \\ 2 - Henan Institute of Science and Technology, Xinxiang, PR China
}

Keywords:

Grinding

Pressure,

Soybean

Fiber

Functionality

\section{Article history:}

Received 02.07.2019

Received in revised

form 24.09.2019

Accepted 30.03.2020

\section{Corresponding}

author:

Jie Zeng

E-mail:

zengjie623@

163.com

DOI: $10.24263 / 2304-$

974X-2020-9-1-11

\section{Abstract}

Introduction. The content of soluble dietary fiber (SDF) and the taste and quality of soybean by-products can be improved by combination of ultrafine grinding-high pressure technology.

Material and methods. Soybean by-products; superfine grinding KCW-701S; high static pressure processing device FPG5620YHL; ultrafine grinding-high pressure technology set pressure:0, 50, 100, 150, 200 and 300MPa; material-liquid ratio: 1:3, 1:5, 1:7, 1:9 and 1:11; time: 5, 10, 15, 20 and 25 min.

Result and discussion. Ultrafine grinding has a significant impact on SDF of soybean by-products. As the frequency decreases, the SDF content gradually increased. When the frequency was $30 \mathrm{~Hz}$, it reached the highest value of $27.11 \%$, and it increased by $8.1 \%$ compared with control. When the frequency was less than $30 \mathrm{~Hz}$, the SDF content drops sharply to $24.12 \%$. Therefore, the ultrafine grinding frequency was the best at $30 \mathrm{~Hz}$, and SDF of soybean by-products was the highest.

When the pressure at $150 \mathrm{MPa}$, the material-liquid ratio was $1: 7$, at $10 \mathrm{~min}$, the content of SDF had reached a maximum of $28.76 \%$ in soybean by-products, which was increased by $12.76 \%$, it compared with the control group.

The water solubility, expansion, water and oil holding capacity of soybean by-products were lower, it compared with the control group. When the pressure at $150 \mathrm{MPa}$, water soluble content was minimum $11.24 \%$. But with the rose in time, the minimum was $10.39 \%$ at $15 \mathrm{~min}$. At $150 \mathrm{MPa}$ for $10 \mathrm{~min}$, the expansion was $8.2 \mathrm{~mL} / \mathrm{g}$, but when the processing time was $20 \mathrm{~min}$, the expansibility was up to $8.8 \mathrm{~mL} / \mathrm{g}$. The water and oil holding capacity of soybean by-products have similar trends. At 100 $\mathrm{MPa}$, the pressure achieved the highest value, at $150 \mathrm{MPa}$, the water and oil holding properties was the smallest, but when the treatment time exceeds $10 \mathrm{~min}$, the water and oil holding properties slightly increased.

Conclusion. The ultrafine grinding frequency at $30 \mathrm{~Hz}$, and SDF of soybean by-products was the highest value of $27.11 \%$. When the pressure was $150 \mathrm{M} \mathrm{Pa}$, the material-liquid ratio was $1: 7$, at $10 \mathrm{~min}$, the SDF of soybean by-products has reached maximum, and it was $28.76 \%$. 


\section{Introduction}

Soybean residue is rich in nutrients, containing $50 \%$ dietary fiber, $25 \%$ protein, $10 \%$ fat, $33 \%$ isoflavones, slightly higher amino acid content than soy milk, as well as calcium, phosphorus, iron and B vitamins. Therefore, soybean by-products have the nutritional characteristics of high fiber, high protein, low fat and low reducing sugar, and is rich in mineral elements of potassium, calcium and magnesium et al [1-4]. Bean by-products had a certain health care function and were a good dietary fiber raw material [5-6]. With the development of nutrition and related disciplines, more and more studies had found that dietary fiber plays a very important role in human health. It was an indispensable nutrient in human healthy diet, especially in the health of digestive tracts. Comprehensively, dietary fiber has physiological functions, such as lower blood fat and blood sugar, improved the intestinal environment, and controlled body weight [ $7-8]$. The bean by-products dietary fiber was mainly composed of cellulose, hemicellulose (dry weight content 40-60 g/100 g) and lignin. Dietary fiber includes soluble and in SDF. However, SDF has a potential "prebiotic" label [9-10]. SDF has high viscosity and strong water holding capacity. It can be used by intestinal microorganisms and slow down the digestion rate. And delay the body's absorption of water compounds by carbon bodies, have a role in decreasing postprandial blood glucose, and improve insulin sensitivity. Ingesting abundant SDF can also accelerate cholesterol excretion, control blood sugar and cholesterol levels, and prevent cardiovascular disease, obesity, diabetes, and other diseases.

The content of SDF and the taste and quality of soybean by-products can be improved by different processing technologies. Nowadays, ultrafine grinding technology can effectively improve the functional properties of bean by-products dietary fiber [11-12]. Ultrafine grinding technology has been extensively used in various fields such as food, chemical, pharmaceutical, cosmetic pesticides, dyes, coatings, electronics and aerospace. High pressure technology refers to the sealing of food materials in an elastic container or pressure-resistant device system, the pressure conditions are generally (100-700 MPa), it often used water or other fluid medium as a medium to achieve sterilization, and change materials, the purpose of physical and chemical properties. In recent years, high pressure technology has been used in the food industry as a new technology, but high pressure was commonly used in meat products, vegetables, beverages, jam and so on. There are few studies on high pressure in cereal products, and most of them are concentrated on cereal starch. It has a modification effect on starch slurry, which can destroy the surface and internal structure particles of starch [13-14]. However, there is likewise a small part in the research of soybean by-products. For example, soybean by-products were processed by high pressure technology, SDF content of soybean by-products can be increased [15-17].

However, the combination of ultrafine grinding-high pressure technology for soybean by-products, there has been no research report. This paper uses soybean by-products as raw materials by ultrafine grinding-high pressure technology to treat soybean by-products. The SDF and functional properties of soybean by-products were analyzed by ultrafine grindinghigh pressure technology. It provides theoretical reference to further research and application of soybean by-products in food. 


\section{Materials and methods}

\section{Material}

Soybean by-products.

\section{Reagent}

Reagents such as absolute ethanol and acetone are of analytical grade.

\section{Instrument}

Superfine grinding KCW-701S; high static pressure processing device FPG5620YHL; multifunctional vacuum packaging machine DRZ-420; electric thermostatic water bathed HWS-26; low-speed desktop centrifuge TDL-40B; electric heating constant temperature blast drying box DHG-9140A.

\section{Experiment methods}

Operating procedures. Soybean by-products $\rightarrow$ hot air drying $\rightarrow$ ultrafine grinding $\rightarrow$ vacuum packaging $\rightarrow$ high pressure $\rightarrow$ dry $\rightarrow$ reserved.

The soybean by-products powder was diluted with water, and the material-liquid ratio was about 1:7. Put it in the packaging bag and seal it, and put it into the machine for high pressure treatment. Freeze the processed raw materials for 24 hours, freeze dry for 48 hours, pass through 80 meshes of sieves and reserve.

The preparation of bean by-products was slightly modified: Used $500 \mathrm{~g}$ of clean soybeans, add $1000 \mathrm{~g}$ of water, soak for $3 \mathrm{~h}$, put in a soybean milk machine to squeeze, and filter out excess water to obtain fresh wet bean by-products [18].

Experimental design. The SDF in soybean by-products as the main index, and determine the optimal frequency of ultrafine grinding. On this basis, high pressure processing, and determined the best conditions. Pressure:0, 50, 100, 150, 200 and $300 \mathrm{MPa}$, in order to save time, for 10 min respectively, material-liquid ratio:1:7. According to the highest SDF content, the pressure conditions are selected. Under a fixed pressure, analyze different material-liquid ratios: 1:3, 1:5, 1:7, 1:9, 1:11, and select the material-liquid ratio of the highest SDF content; Then determine the different processing time:5, 10, 15, 20 and $25 \mathrm{~min}$. It can be concluded under what conditions the bean dregs has the highest SDF content, and analyzed the functional properties in soybean by-products of ultrafine grinding- high pressure technology.

Effect of ultrafine grinding - high pressure technology and ultrafine grinding frequency on SDF of soybean by-products. Effect of different pressure, material-liquid ratio and processing time on SDF of ultrafine soybean by-products powder. Determination of SDF:GB/T 37492-2019 «Inspection of grain and oils - Determination of SDF in cereals and cereals products - Enzyme gravimetric method».

Effect of high pressure on functional properties, different pressures on water solubility content, treatment time on water solubility content of ultrafine soybean by-products powder. Refer to [19]. A sample of $0.500 \mathrm{~g}$ of soybean by-products was weighed and placed in 200 $\mathrm{mL}$ beakers. $50 \mathrm{~mL}$ of distilled water was weighed and placed in a constant temperature water bath at $90{ }^{\circ} \mathrm{C}$ for constant stirring. After $30 \mathrm{~min}$, centrifuge at $3000 \mathrm{r} / \mathrm{min}$ for $15 \mathrm{~min}$, pour the resulting supernatant into a Petri dish, and dry to a constant weight at $105^{\circ} \mathrm{C}$ to weigh the residue (the total mass of the Petri dish and residue - Petri dish quality).

$$
\text { Water solubility }=\frac{\text { Residue mass }}{\text { Sample quality }} \times 100 \% \text {. }
$$


Effect of different pressures and treatment time on expansion of ultrafine soybean byproducts powder. Measurement method was referred to [20-22]. Weigh $1.000 \mathrm{~g}$ of the sample of a container with a graduated surface, add $10 \mathrm{~mL}$ of distilled water, stir, and let it stand at room temperature for $24 \mathrm{~h}$. Record the volume of the sample at this time.

Calculation method: set the sample mass to $\mathrm{N}_{0}$, and the expanded volume was $\mathrm{N}_{1}$ expansion $=$ Volume after expansion $\div$ Sample mass $\times 100 \%$.

$$
\text { Expansion }=\frac{N_{1}}{N_{0}} \times 100 \% \text {. }
$$

Effect of different pressures and treatment time on expansion of ultrafine soybean byproducts powder. Determination of water holding capacity $(W H C)$ : weigh about $0.2 \mathrm{~g}$ of soybean by-products into a centrifuge tube, add $10 \mathrm{~mL}$ of water, stir evenly, place at room temperature for $1 \mathrm{~h}$, centrifuge at $3000 \mathrm{r} / \mathrm{min}$ for $20 \mathrm{~min}$, discard the supernatant, and weight of the centrifuge tube $[20,21]$.

$$
W H C=\left(m_{1}-m_{2}-m_{3}\right) / m_{3}
$$

where $m_{1}$ - centrifuge tube and residue mass after centrifugation; $m_{2}$ - centrifuge tube mass; $m_{3}$ - dry weight of sample.

Effect of different Pressures treatment time and on oil holding capacity $(\mathrm{OHC})$ of place it in a constant weight centrifuge tube, add $5 \mathrm{~mL}$ of soybean oil, mix well, and let it stand for $30 \mathrm{~min}$, shaking once every $5 \mathrm{~min}$. After that, centrifuge at $4500 \mathrm{r} / \mathrm{min}$ for $25 \mathrm{~min}$ to remove the upper loose fat and weigh the total mass of the centrifuge tube and residue [23].

$$
O H C=\left(m_{1}-m_{2}-m_{3}\right) / m_{3}
$$

where $m_{1}$ - centrifuge tube and residue total mass; $m_{2}$ - centrifuge tube mass; $m_{3}-$ sample mass.

Statistical designs and data analysis. All data were assayed at least three times and the results were expressed as mean standard deviation $(\mathrm{x} \pm \mathrm{SD})$. Data and mapping were analyzed used statistical software WPS (Excel), and SPSS analysis software was utilized to test. The level on which significant differences were reported was setting $\mathrm{p}<0.05$.

\section{Results and discussion}

\section{Effect of ultrafine grinding frequency on SDF of soybean by-products}

As can be seen from Figure 1, ultrafine grinding significantly increased the content of SDF in soybean by-products, compared with ordinary pulverization technology. When the frequency at 40 and $30 \mathrm{~Hz}$, the SDF content was $27.03 \%$ and $27.11 \%$, and the difference was significant, compared with other results $(p<0.05)$. When the ultrafine grinding frequency at $20-10 \mathrm{~Hz}$, the content of SDF suddenly drops. This was because part of the structure of the bean by-products was damaged during crushing. Insoluble hemicellulose and insoluble pectin compounds, melting phenomenon or partial bond breakage. Thereby, it was transformed into a small soluble molecule substance, which leads to increase to SDF in soybean by-products [24-26]. Below $30 \mathrm{~Hz}$, the structure of the soybean by-products was severely damaged, and the powder particles reached a certain fineness, which causes the small particles to aggregate with each other, adhere to the inner wall of the machine cavity, and the output rate decreases, which hinders the release of SDF in the soybean by-products. At this time, the molecular structure of soybean by-products tended to be stable, and there was no further changed, and the content of SDF also remained basically unchanged [27]. Therefore, when the ultrafine grinding frequency at $30 \mathrm{~Hz}$, the SDF content reached a maximum of $27.11 \%$, which was $8.1 \%$ higher than ordinary pulverization. Coupled with the previous research results [28], 
When the frequency at $30 \mathrm{~Hz}$, the soluble dietary fiber content of soybean by-products was the highest.

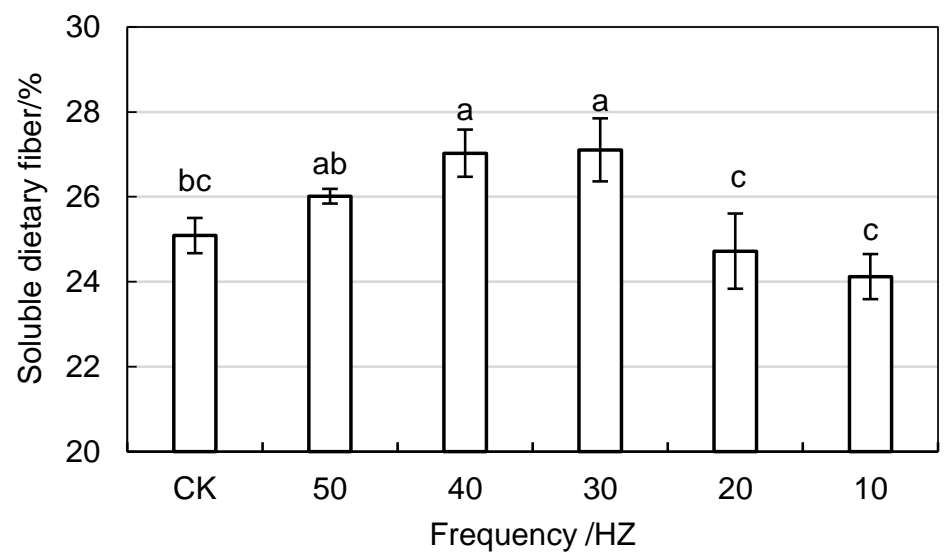

Figure 1. Effect of ultrafine grinding Frequency on SDF of soybean by-products

${ }^{a-c}$ Different parameter superscripts in the figure indicate significant differences $(p<0.05)$

Effect of ultrafine grinding - high pressure technology on SDF of soybean byproducts. Effect of different pressure on SDF of ultrafine soybean by-products powder

It generally considered that the pressure exceeding $100 \mathrm{MPa}$ was high pressure. It can be seen from Figure 2 that different pressure has a greater impact on the solubility of soybean by-products.

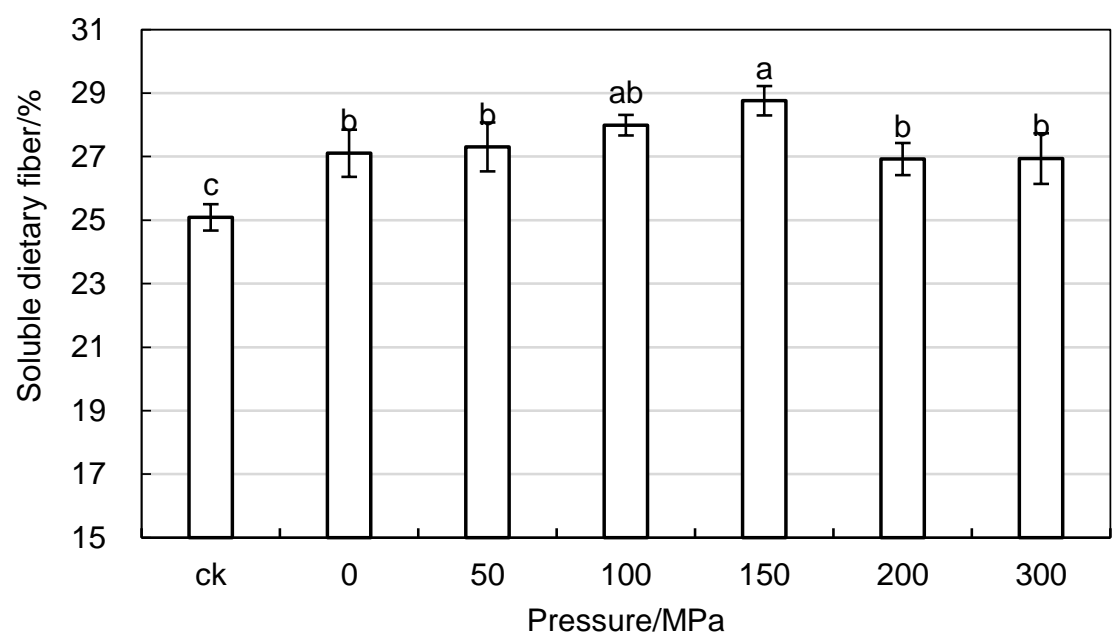

Figure 2. Effect of different pressure on SDF of ultrafine soybean by-products powder ${ }^{a-d}$ Different parameter superscripts in the figure indicate significant differences $(p<0.05)$

With increasing pressure, the content of SDF in soybean by-products gradually increased. When the pressure was $150 \mathrm{MPa}$, the content of SDF reached a maximum of 
$28.76 \%$, an increase of $12.76 \%$ compared with the control group, and an increase of $5.7 \%$ compared with ultrafine grinding $(0 \mathrm{MPa})$. When the pressure at $300 \mathrm{MPa}$, the content of SDF in soybean by-products dropped to $26.94 \%$, and it was located in a stable trend. When the bean by-products were subjected to ultrafine grinding, the cohesive force inside the bean by-products was broken, and the particle size becomes fine. On this basis, high pressure processing and instantaneous processing have produced extremely high static pressure and accompanying forces, which can change the dense tissue structure of bean by-products, so that SDF was made public from the cells [29]. Therefore, ultrafine grinding-high pressure technology can significantly increase the content of SDF in soybean by-products. Among them, SDF content of soybean by-products obtained was the highest at $150 \mathrm{MPa}$.

\section{Effect of material-liquid ratio on SDF of ultrafine soybean by-products powder}

It can be seen from Figure 3 that different material-liquid ratios have a great influence on the SDF of soybean by-products. Due to the strong water absorption of soybean byproducts, at 1:3, the soybean by-products did not get sufficient water absorption, and the degree of destruction under high pressure was insufficient, so the SDF content was low. However, with the increase of water content, the content of SDF gradually increased. The value was the highest and reached $28.76 \%$. However, with the increase of water content, when the material-liquid ratio exceeds $1: 9$, the paste was thin and susceptible to precipitation. Precipitation may occur in the compression process. The structure of the space where the bean by-products gather with each other changes, and the release of SDF content was limited. Therefore, SDF content was the highest by high pressure, when the ratio of material to liquid was 1:7. Treated soybean by-products under high pressure, used water as a pressure transmitting medium, thereby destroy the internal structure of soybean by-products. The combined effect of pressure and moisture was the main reason for the increase in SDF content [30].

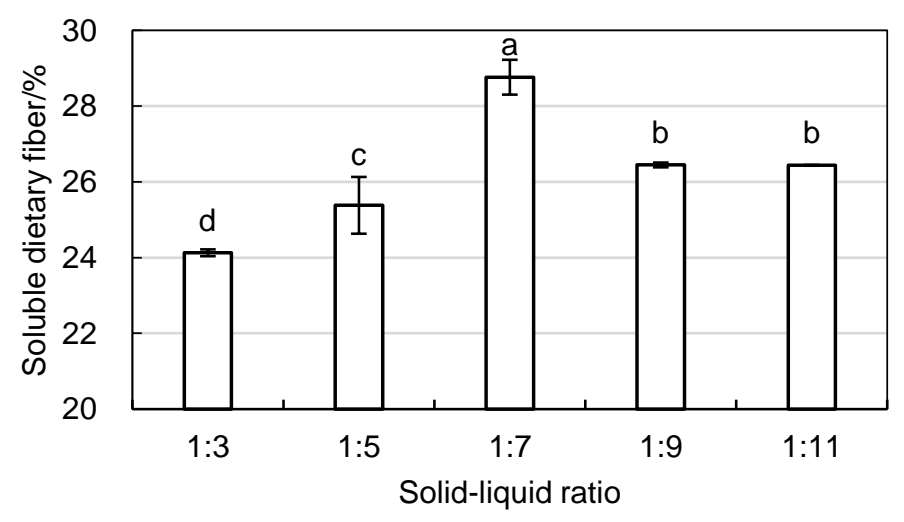

Figure 3. Effect of material-liquid ratio on SDF of ultrafine soybean by-products powder ${ }^{a-d}$ Different parameter superscripts in the figure indicate significant differences $(p<0.05)$ 


\section{Effect of processing time on SDF of ultrafine soybean by-products powder}

It can be seen from Figure 4 that different times has a greater influence on the solubility of soybean by-products. When the processing pressure at $150 \mathrm{MPa}$ and the material-liquid ratio was 1:7, when the cycle of 1 , With the continuous extension of the high pressure treatment time, the SDF content of soybean by-products gradually increased. When the time for $10 \mathrm{~min}$, the maximum content of SDF in soybean by-products was $28.76 \%$. Compared with ultrafine grinding $(0 \mathrm{MPa})$, it was $5.7 \%$ higher. When the treatment time exceeds 10 $\mathrm{min}$, the content of SDF in soybean by-products gradually decreases, and after $20 \mathrm{~min}$, it was basically in a stable trend. Therefore, treatment for $10 \mathrm{~min}$ has a great influence on the content of SDF of soybean by-products.

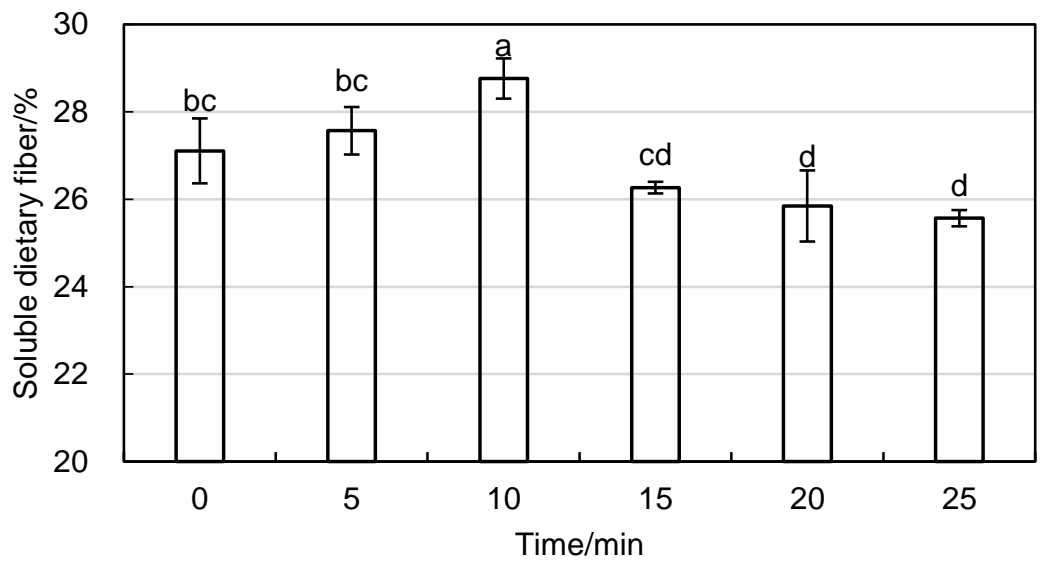

Figure 4. Effect of processing time on SDF of ultrafine soybean by-products powder ${ }^{a-d}$ Different parameter superscripts in the figure indicate significant differences $(p<0.05)$

Effect of high pressure on functional properties of ultrafine soybean by-products powder. Effect of different Pressures on water solubility content of ultrafine soybean by-products powder

It can be seen from Figure 5 that when the pressure $0 \mathrm{MPa}(30 \mathrm{~Hz})$, the water solubility content reached $20.84 \%$, which was significantly different from the other groups $(p<0.05)$. Compared with ordinary soybean by-products $(\mathrm{CK})$, the water solubility was increased by $73.38 \%$. However, with the increase of pressure, the water solubility content gradually showed a downward trend. At $150 \mathrm{MPa}$, the effect was the greatest, and the lowest water solubility content was $11.24 \%$. This may be explained by the bean by-products were rubbed by mechanical force during crushing. The resultant force was applied to the high pressure treatment. The soybean by-products were damaged under a certain pressure, the protein existing on the bean by-products was denatured, the hydrophobic groups were turned out, and the hydrophilicity was greatly reduced, which leads to the easy precipitation of the proteins and affects the water solubility of the soybean by-products. Therefore, different pressure can affect the water solubility of soybean by-products of ultrafine grinding-high pressure technology treatment. 


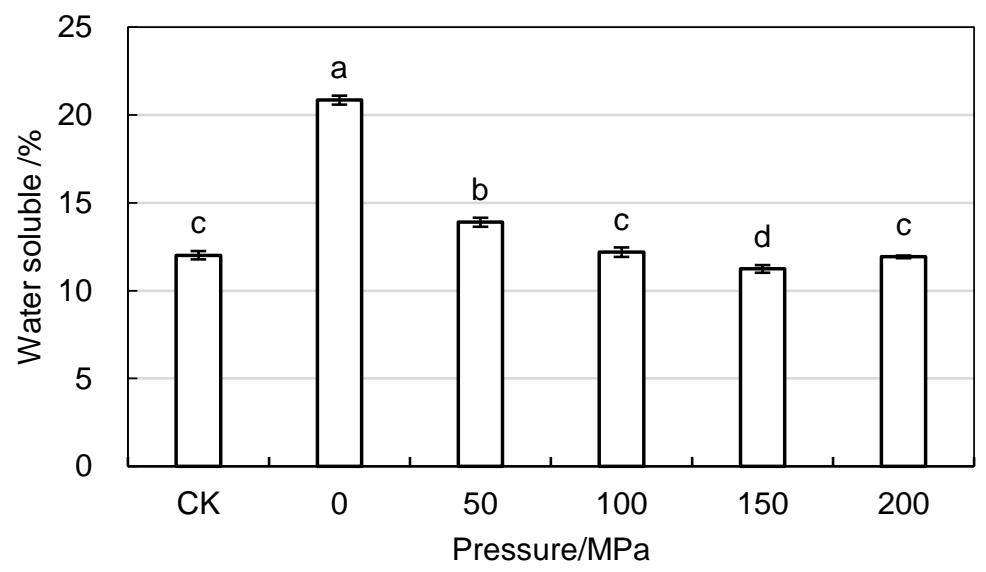

Figure 5. Effect of different Pressures on water solubility content of ultrafine soybean by-products powder

${ }^{a-d}$ Different parameter superscripts in the figure indicate significant differences $(p<0.05)$

\section{powder}

Effect of different Pressures on expansion of ultrafine soybean by-products

The expansibility forced means that the fibrous substance in the material will increase to volume after absorbing water, forming a certain feeling of satiety in the human stomach and intestines. As can be seen from Figure 6. the expansion of soybean by-products reached the minimum by ultrafine grinding-high pressure technology treatment. However, with the increase of pressure, the expansibility of the bean by-products powder gradually increased. The expansibility property was $7.8 \mathrm{~g} / \mathrm{mL}$, at $50 \mathrm{MPa}$, but there was almost no obvious change in the range of 100-150 $\mathrm{MPa}$. Therefore, change of expansibility properties of superfine grinding-high pressure treated soybean by-products was mainly affected by pressure.

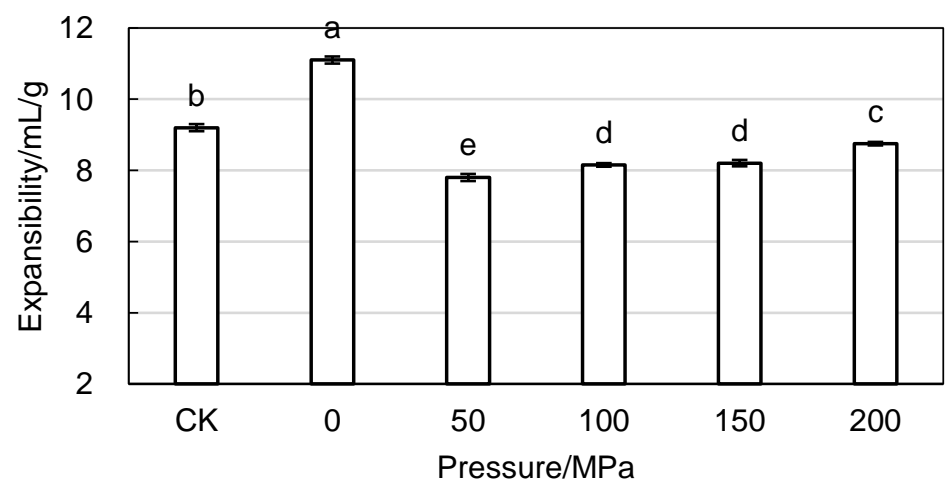

Figure 6. Effect of different Pressures on expansibility of ultrafine soybean by-products powder ${ }^{a-e}$ Different parameter superscripts in the figure indicate significant differences $(p<0.05)$ 
This phenomenon may be that the soybean by-products undergo a secondary change in the spatial network structure. Under certain pressure conditions, and some of the capillary structure was damaged, which reduces its ability to restrain water molecules and causes the powder to expand weakly. It was the same as Cheng Jiao-Jiao research conclusion [31].

\section{Effect of different pressures on water holding capacity of ultrafine soybean by- products powder}

The water holding capacity of soybean by-products indicates its ability to absorb water. It can be seen from Figure 7 that the maximum water holding capacity of ordinary dregs (CK) was $10.92 \mathrm{~g} / \mathrm{g}$, which was significantly different from other groups $(\mathrm{p}<0.05)$. The ultrafine grinding - high pressure treatment makes the overall capacity of water retention of soybean by-products lower, but when the pressure was $100 \mathrm{MPa}$, water holding capacity reaches 5.73 $\mathrm{g} / \mathrm{g}$, when it was above $150 \mathrm{MPa}$, it gradually shows a stable trend. This may be the ultrafine grinding treatment, so that more long-chain molecules in the dietary fiber molecules were converted into short-chain small molecules, adding more hydrophilic groups. After high pressure treatment again, the binding force of the molecular hydrophilic groups was instantly weakened, and the water cannot be blocked. Under high-speed centrifugation, water molecules in the material cannot be found. Therefore, ultrafine grinding-high pressure treatment reduces the water holding capacity of soybean by-products [32].

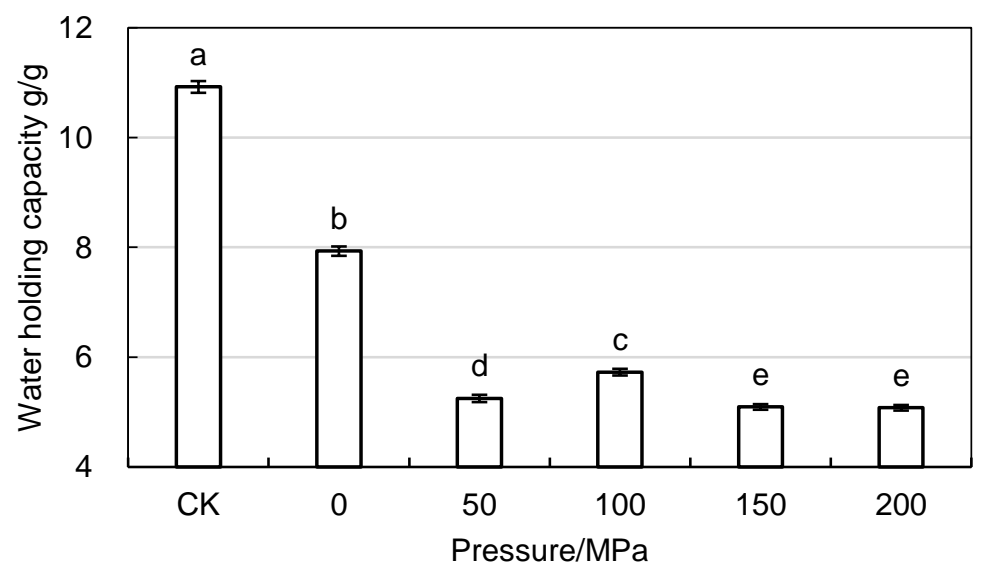

Figure 7. Effect of different Pressures on water holding capacity of ultrafine soybean by-products powder

a-e Different parameter superscripts in the figure indicate significant differences $(p<0.05)$

\section{Effect of different Pressures on oil holding capacity of ultrafine soybean by- products powder}

The dietary fiber in soybean by-products can absorb the fat in food and excrete it from the body, reduce saturated fatty acids in the human body, and achieve weight loss. It can be seen from Figure 8 that under high pressure treatment, the oil holding capacity and water holding capacity of soybean by-products powder were similar, which were smaller than those of other groups, and the overall maximum were $51 \%$, a significant difference $(p<0.05)$. 
Under the action of ultrafine grinding (0), the space structure of bean by-products was opened, and the fat is retained in the gap. The high pressure force once again destroys the inside of the soybean by-products, forming a multi-level space. At this time, the structure was relatively loose, causing the oil inside the soybean by-products cells to flow out, attach to the surface of the bean by-products, and weaken the interaction with the vegetable oil. Under the action of centrifugal force, the ability of soybean by-products to bear fat becomes weak. Therefore, ultrafine grinding-high pressure treatment makes the oil holding power of soybean by-products powder weaken, which has a greater relationship between the pressure.

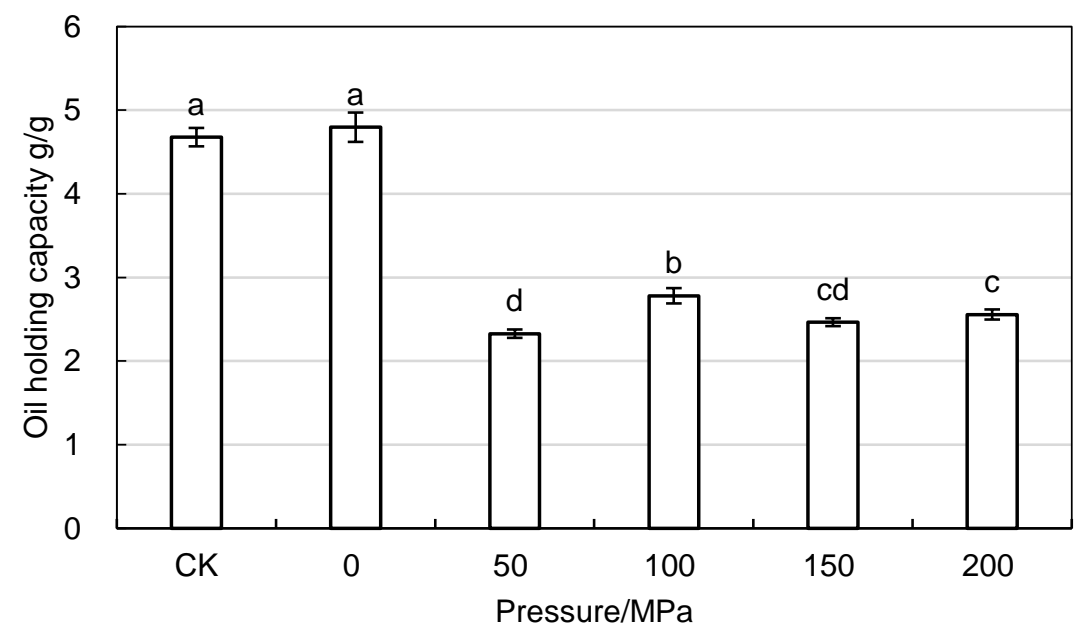

Figure 8. Effect of different Pressures on oil holding capacity of ultrafine soybean by-products powder

${ }^{a-d}$ Different parameter superscripts in the figure indicate significant differences $(p<0.05)$

Effect of high pressure treatment times on functional properties of ultrafine soybean by-products powder. Effect of treatment times on water solubility content of ultrafine soybean by-products powder

It can be seen from Figure 9 that the soybean by-products undergo a high pressure treatment, and the water solubility content changes drastically with the increase of the treatment time. When the treatment time was $5 \mathrm{~min}$, the water solubility content was $11.51 \%$, which was a decrease of $44.77 \%$, compared to other treatments, which were significant $(\mathrm{p}<0.05)$. When the processing time was $10 \mathrm{~min}$, the highest water soluble content was $11.24 \%$, and when the processing time was $15 \mathrm{~min}$, the lowest water solubility content was $10.39 \%$. When the treatment time was above $20 \mathrm{~min}$, the water solubility content does not change significantly. It shows that the processing time was between 10-15 min, the structure of the soybean by-products changes, the protein was denatured, and the hydrophilicity was weakened, which affects the water solubility of the bean by-products. 


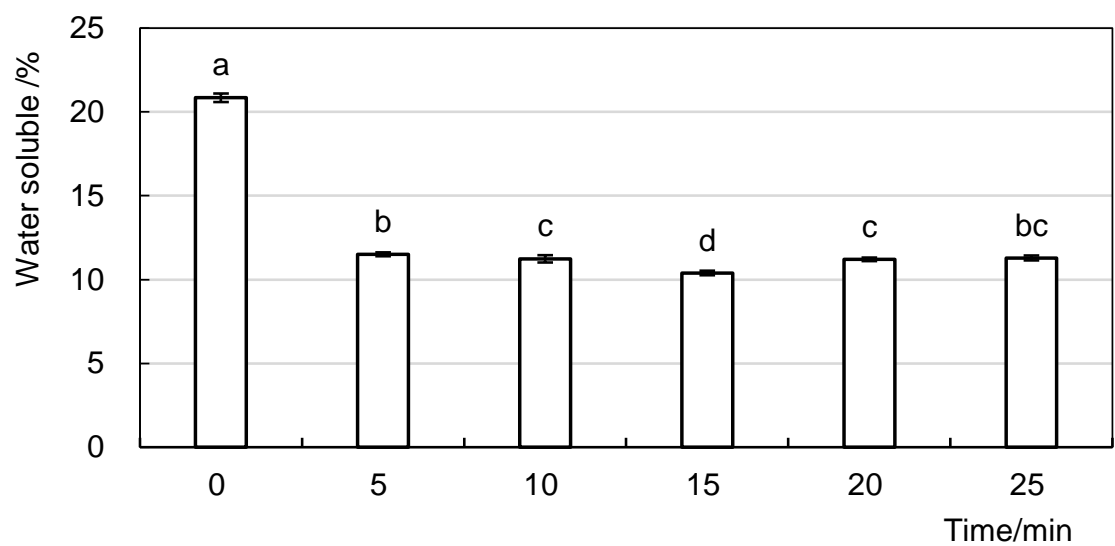

Figure 9. Effect of treatment time on water solubility content of ultrafine soybean by-products powder

a-d Different parameter superscripts in the figure indicate significant differences $(p<0.05)$

Effect of treatment times on expansion of ultrafine soybean by-products powder.

It can be seen from Figure 10 that expansibility property of the soybean by-products was lower than $0 \mathrm{MPa}$ as a whole, and the difference was significant $(\mathrm{p}<0.05)$. It was demonstrated that when soybean by-products enter the high pressure cavity for $5 \mathrm{~min}$, an instantaneous pressure difference can be generated, and the structure of soybean by-products begins to loosen. As time is there, a multi-dimensional network structure was gradually formed into the soybean by-products, which can absorb more moisture, which results in an increase in expansibility. The expansion at $20 \mathrm{~min}$ was the highest at $8.8 \mathrm{~mL} / \mathrm{g}$. But more than $20 \mathrm{~min}$, the space structure of soybean by-products gradually closed, the bearing moisture weakened, resulting in reduced expansibility.

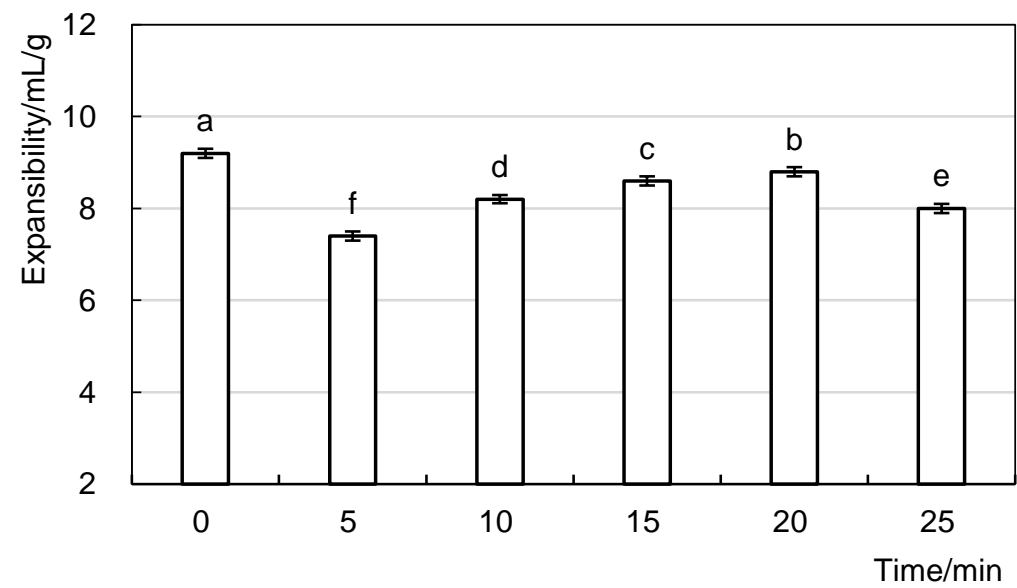

Figure 10. Effect of treatment time on expansion of ultrafine soybean by-products powder ${ }^{a-f}$ Different parameter superscripts in the figure indicate significant differences $(p<0.05)$ 


\section{Effect of treatment time on water holding capacity of ultrafine soybean by- products powder}

It can be seen from Figure 11 that after different treatment time, the water holding capacity of the soybean by-products was lower than $0 \mathrm{MPa}$. However, as time is there, the water holding capacity of soybean by-products was picking up. At $10 \mathrm{~min}$, the water holding capacity was the weakest, and the structure of the soybean by-products was probably the most loose. The soybean by-products cannot support the absorbed moisture, especially under the action of centrifugal force. The bearing capacity was weak, resulting in poor water holding capacity. But at $25 \mathrm{~min}$, the water holding capacity maximum was $7.21 \mathrm{~g} / \mathrm{g}$, which indicates that under this condition, the structure of soybean by-products changed from loose and porous to aggregate, the particles condensed with each other, and the binding force of water was tight.

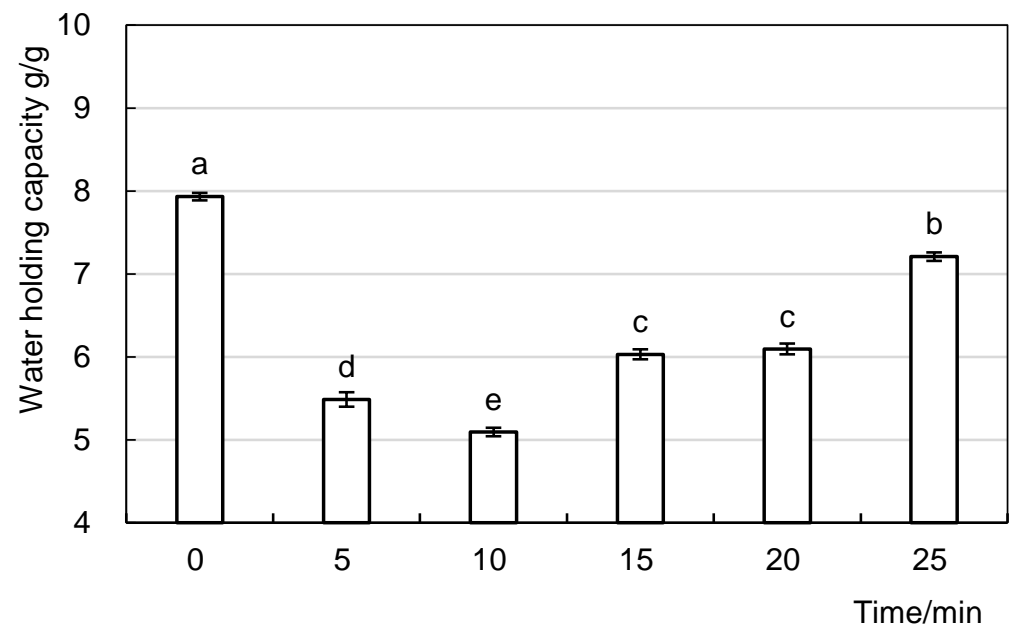

Figure 11. Effect of treatment time on water holding capacity of ultrafine soybean by-products powder

${ }^{a-d}$ Different parameter superscripts in the figure indicate significant differences $(p<0.05)$

\section{Effect of treatment time on oil holding capacity of ultrafine soybean by-products powder}

It can be seen from Figure 12 that weakest oil holding capacity was $2.47 \mathrm{~g} / \mathrm{g}$ at $10 \mathrm{~min}$, which was $48.54 \%$ lower than that of the control group, but the oil-holding capacity increased significantly when the treatment time was above $15 \mathrm{~min}$. At $25 \mathrm{~min}$, the oil retention was 5.96 $\mathrm{g} / \mathrm{g}$. It shows that the structure of ultrafine soybean by-products powder has undergone a series of changes for 5-25 min compression. After processing for 5-10 min, the structure of the soybean by-products was gradually opened. At this time, a small amount of oil enters the inside and the surface of the soybean by-products, but the bearing capacity of the soybean by-products was weak, and it was difficult to block the oil. At 15-25 min, the spatial structure of soybean by-products gradually changed from open to closed. With the extension of time, when the processing time was $25 \mathrm{~min}$, the soybean by-products particles were aggregated with each other, which causes the internal oil to be restrained, and the oil holding capacity for the highest. 


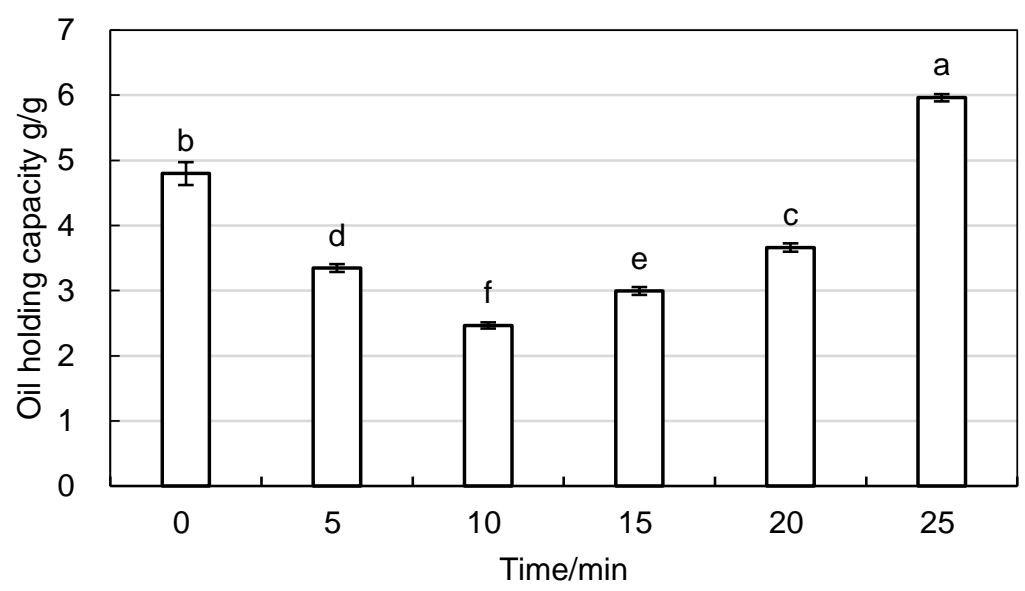

Figure 12. Effect of treatment time on oil holding capacity of ultrafine soybean by-products powder

${ }^{\text {a-f }}$ Different parameter superscripts in the figure indicate significant differences $(p<0.05)$

\section{Conclusion}

The SDF of soybean by-products has a significant effect by ultrafine grinding. As the frequency decreases, the SDF content gradually increased. When the frequency was $30 \mathrm{~Hz}$, the highest value was $27.11 \%$, which was $8.1 \%$ higher than the control. This could be caused by the structure of soybean by-products was damaged in a specific frequency range. Insoluble hemicellulose, and insoluble pectin compounds undergo melting or partial bond breakage, converted into soluble small molecular substances, increasing the SDF content. When the frequency was less than $30 \mathrm{~Hz}$, the content of SDF dropped sharply to $24.12 \%$. When the powder reached a certain fineness, the small particles aggregate with each other, hindering the release of SDF in the soybean by-products, and a part from the soybean byproducts powder adheres to the inner wall of the machine cavity, and the discharge rate was reduced. Therefore, the ultrafine grinding frequency at $30 \mathrm{~Hz}$, and the content of SDF in soybean by-products was the highest.

High pressure treatment was performed on the basis of ultrafine grinding. With the increased in pressure, the content of SDF in soybean by-products moderately increased. When the over pressure at $150 \mathrm{MPa}$, the content of SDF in soybean by-products reached maximum was $28.76 \%$, which was $12.76 \%$ higher than the control group, and $5.7 \%$ higher than ultrafine grinding $(0 \mathrm{MPa})$. When the pressure was greater than $150 \mathrm{MPa}$, the content of $\mathrm{SDF}$ in soybean by-products decreased to $26.94 \%$, and it was stable at $300 \mathrm{MPa}$. When the soybean by-products were subjected to ultrafine grinding, the cohesive force inside the bean by-products was broken, and the particle size becomes fine. On this basis, high pressure processing and instantaneous processing have produced extremely high static pressure and accompanying forces, which can change the dense tissue structure of bean by-products, so that SDF was released from the cells. With the increased in pressure, the cell wall of soybean by-products was a process from relaxation to destruction. Above $200 \mathrm{MPa}$, the soybean byproducts were severely damaged, which instead affects the dissolution of the SDF content, it was not that the higher the pressure, the higher the SDF content. Therefore, ultrafine grinding- 
high pressure technology treatment can significantly improve the SDF of soybean byproducts at $150 \mathrm{MPa}$.

When the material - liquid ratio was 1:3, the soybean by-products do not get sufficient water absorption, and the SDF content was low. The material-liquid ratio was 1:7, and the viscosity of the paste was moderate. At this time, the highest value was $28.76 \%$. However, with the increased of water content, when the material-liquid ratio exceeds 1:9, the paste was thin and susceptible to precipitation. At this time, the content of SDF in soybean by-products gradually decreased. Therefore, the optimum condition of the material-liquid ratio was 1:7. Used water as a balanced transmission medium for pressure, the combined effect of pressure and moisture was the main reason for the increased in SDF content of soybean by-products.

With the continuous increased in treatment time, the content of SDF of soybean byproducts gradually increased. When the processing time was $10 \mathrm{~min}$, the SDF content reached a maximum, it was $28.76 \%$, longer than $10 \mathrm{~min}$, it gradually decreased, and it was basically stable after $20 \mathrm{~min}$. Therefore, the processing time was $10 \mathrm{~min}$, and the content of SDF was the highest in soybean by-products.

The water solubility, expansibility, water and oil holding capacity of soybean byproducts were lower, by ultrafine grinding and high pressure technology, than those of the control group. When the pressure at $150 \mathrm{MPa}$, the minimum water-soluble content was $11.24 \%$, but with the increased of processing time, the minimum was $10.39 \%$ at $15 \mathrm{~min}$. The expansibility of bean dregs was $8.2 \mathrm{~mL} / \mathrm{g}$ at $150 \mathrm{MPa}$ for $10 \mathrm{~min}$. Nevertheless, when the processing time was $20 \mathrm{~min}$, the maximum expansibility was $8.8 \mathrm{~mL} / \mathrm{g}$. The water and oil holding capacity of soybean by-products have similar trends. In the high pressure range, the pressure reached the highest value at $100 \mathrm{MPa}$. At $150 \mathrm{MPa}$, the water and oil holding capacity were the smallest. However, when the treatment time at $150 \mathrm{MPa}$ exceeds $10 \mathrm{~min}$, the water and oil holding capacity gradually increased.

Therefore, the pressure and time has a significant impact on soybean by-products. Comprehensively shows that the pressure at $150 \mathrm{MPa}$, the material-liquid ratio was 1:7 for 10 min by ultrafine grinding-high pressure technology, the content of SDF in soybean byproducts reached maximum, it was $28.76 \%$. Compared with the control group, it was increased by $12.76 \%$, and it was increased by $5.7 \%$, compared with ultrafine grinding ( 0 $\mathrm{MPa}$ ). This conclusion can provide an important basis of the development of SDF food.

\section{References}

1. Li B., Qiao M., \& Lu F. (2012), Composition, nutrition, and utilization of okara (soybean residue), Food Reviews International, 28(3), pp. 231-252.

2. Bowles S., Demiate I. M. (2006), Physicochemical characterization of the soymilk by product-okara, Food Science and Technology, 26(3), pp. 652-659.

3. Iskander F. Y. (1987), Maturation stage and mineral content in soybeans, Food chemistry, 24(1), pp. 29-35.

4. Wang D.L., Li B., Lu. F., \& Nan H. J. (2010), Analysis of Nutrient Components of Bean Curd Residue, Food and Fermentation Technology, 46(04), pp. 85-87.

5. Bourquin L. D., Titgemeyer E. C., \& Fahey Jr. G. C. (1996), Fermentation of various dietary fiber sources by human fecal bacteria, Nutrition Research, 16(7), pp. 1119-1131.

6. Tharanathan R. N., \& Mahadevamma S. (2003), Grain legumes - a boon to human nutrition, Trends in Food Science \& Technology, 14(12), pp. 507-518. 
7. Chutkan R., Fahey G., Wright W. L., \& McRorie J. (2012), Viscous versus nonviscous soluble fiber supplements:Mechanisms and evidence for fiber-specific health benefits, Journal of the American Academy of Nurse Practitioners, 24(8), pp. 476-487.

8. Mehta N., Ahlawat S. S., Sharma D. P., \& Dabur R. S. (2015), Novel trends in development of dietary fiber rich meat products - a critical review, Journal of food science and technology, 52(2), pp. 633-647.

9. Gibson G. R., \& Roberfroid M. B. (1995), Dietary modulation of the human colonic microbiota:introducing the concept of prebiotics, The Journal of nutrition, 125(6), pp. 1401-1412.

10. Fuller R., \& Gibson G. R. (1997), Modification of the intestinal microflora using probiotics and prebiotics, Scandinavian Journal of Gastroenterology, 32(sup222), pp. 28-31.

11. Tian S. J., Xie Y. F., Ma Y., et al. (2014), Application of ultrafine grinding soybean byproducts in noodles, Science and Technology of Cereals, Oils and Foods, 22(2), pp. $22-$ 25.

12. Xie Y. F., Tian S, J., Ma Y. (2014), Effect of ultrafine grinding on functional properties of okara, Food \& Machinery, 2, pp. 7-11.

13. Alvarez M. D., Fuentes R., Olivares M. D., \& Canet W. (2014), Effects of high hydrostatic pressure on rheological and thermal properties of chickpea (Cicer arietinum L.) flour slurry and heat-induced paste, Innovative food science \& emerging technologies, 21, pp. 12-23.

14. Hu X. P., Zhang B., Jin Z. Y., Xu X. M., \& Chen H. Q. (2017), Effect of high hydrostatic pressure and retrogradation treatments on structural and physicochemical properties of waxy wheat starch, Food Chemistry, 232, pp. 560-565.

15. Zhang X. (2011, Integrated Research for Extraction of Potato Pulp SDF and Recovery of Precious Metals from Copper Mineral, Northwest Normal University, 1, pp. 1-74.

16. Shao Z. (2016, Research on Improvement of Soybean Residue Soluble Dietary Fiber Content by Physical Treatment, Tianjin University of Science \& Technology, pp. 1-65.

17. Mateos-Aparicio I., Mateos-Peinado C., \& Rupérez P. (2010), High hydrostatic pressure improves the functionality of dietary fiber in okara by-product from soybean, Innovative Food Science \& Emerging Technologies, 11(3), pp. 445-450.

18. Cui S. N., Dong S. S., Qiu L. X., \& Xie W. (2019), Study on the technology of bean dregs nougat, China Fruit and Vegetable, (9), pp. 5-9.

19. Li M. J., Zhang Y. Y. You, X. R. (2015), Banana biscuit processing technology, Science and Technology of Food Industry, 36(3), pp. 204-208.

20. Rupérez P., \& Saura-Calixto F. (2001), Dietary fiber and physicochemical properties of edible spanish seaweeds, European Food Research and Technology, 212(3), pp. 349354.

21. Chau C. F., \& Huang Y. L. (2003), Comparison of the chemical composition and physicochemical properties of different fibers prepared from the peel of Citrus sinensis L. Cv. Liucheng, Journal of Agricultural and Food Chemistry, 51(9), pp. 2615-2618.

22. Turnbull C. M., Baxter A. L., \& Johnson S. K. (2005), Water-binding capacity and viscosity of Australian sweet lupin kernel fibre under in vitro conditions simulating the human upper gastrointestinal tract, International journal of food sciences and nutrition, 56(2), pp. 87-94.

23. Tu Z. C., Chen L. L., Wang H. (2014), Effects of Fermentation and Dynamic High Pressure Microfluidization on Physicochemical Properties of Dietary Fiber in Soybean Residue, Chinese Journal of High Pressure Physics, 28(1), pp. 113-119. 
24. Ramirez-Santiago C., Ramos-Solis L., Lobato-Calleros C. (2010), Enrichment of stirred yogurt with SDF from pachyrhizus erosus 1. urban:effect on syneresis, microstructure and rheological properties, Journal of Food Engineering, 101(3), pp. 229-235.

25. Xia Y. Y., \& Lu Y. W. (2007, Research progress of improving soluble modification of soybean dregs dietary fiber, Cereals and Oils, (07), pp. 113-115.

26. Li L., Zhang H., Wang X.G. (2009), Effect of super micro-milling on the physicochemical properties and composition of dietary fiber prepared from defatted rice bran, China Oils and Fats, 34(2), pp. 56-59.

27. Yang F. L., Y L., \& Wang, Y. Y. (2015), Effects of superfine grinding on the properties of buckwheat bran, Grain and Oil, (02), pp. 21-23.

28. Wang F., Valerii Sukmanov, Zeng J. (2019), Effect of ultrafine grinding on functional properties of soybean by-products, Ukrainian Food Journal, 8(4), pp. 687-698.

29. Suya H., Yawen H. E., Bingjun Q., Yanping Z., \& Zhuang, L. (2015), Modification of insoluble dietary fiber in okara by high pressure homogenization and high hydrostatic pressure and functional properties of the modified product, Food Science, (15), pp. $107-$ 111.

30. Xiong H.W. (2006), On the possibility of using instantaneous high pressure treatment to modify properties of dietary fiber, (Doctoral dissertation, Nanchang University), pp. $1-114$.

31. Cheng J.J. (2018), Study on drying method of soybean by-products and its modification technology, (Master's thesis, Shaanxi University of Science \& Technology), pp. 1-78.

32. Zhang Y. Q., (2011), Optimum process research of extraction and modification on wheat bran dietary fiber, (Doctoral dissertation, QiLu university of technology), pp. 1-57. 